\title{
A Kinetic Model of Municipal Sludge Degradation During Non-catalytic Wet Oxidation
}

\author{
Arrian Prince-Pike, David I Wilson* \\ Department of Electrical \& Electronic Engineering, AUT University, 21 St Pauls St, \\ Auckland, New Zealand \\ Saeid Baroutian* \\ Department of Chemical \& Materials Engineering, Faculty of Engineering, The University \\ of Auckland, 20 Symonds St, Auckland, New Zealand \\ John Andrews and Daniel J Gapes* \\ Scion, Te Papa Tipu Innovation Park, 49 Sala St, Rotorua, New Zealand
}

\begin{abstract}
Wet oxidation is a successful process for the treatment of municipal sludge. In addition, the resulting effluent from wet oxidation is a useful carbon source for subsequent biological nutrient removal processes in wastewater treatment. Owing to limitations with current kinetic models, this study produced a kinetic model which predicts the concentrations of key intermediate components during wet oxidation. The model was regressed from lab-scale experiments and then subsequently validated using data from a wet oxidation pilot plant. The model was shown to be accurate in predicting the concentrations of each component, and produced good results when applied to a plant 500 times larger in size. A statistical study was undertaken to investigate the validity of the regressed model parameters. Finally the usefulness of the model was demonstrated by suggesting optimum operating conditions such that volatile fatty acids were maximised.
\end{abstract}

Keywords: Wet oxidation, municipal sludge, kinetic modelling, wastewater

\footnotetext{
${ }^{*}$ Corresponding author

Email address: david.wilson@aut.ac.nz (Arrian Prince-Pike, David I Wilson)
} 


\section{Introduction}

Municipal sludge is the semi-solid residue remaining at the end of a municipal wastewater treatment process. The treatment of municipal sludge is becoming increasingly important as current disposal methods such as landfill are not sustainable, G et al. (2005), and regulations surrounding sludge disposal are becoming more restrictive, (an indicative example being Potts (2003)). This is intensifying the search for alternative disposal and treatment processes that can address the unique challenges that municipal sludge present, in particular the high water content and the presence of pathogens.

One attractive wastewater treatment alternative is wet oxidation. Wet oxidation is the liquid phase treatment of organic or oxidisable inorganic compounds at elevated temperature and pressure, typically using using oxygen as an oxidant (applied as air or pure oxygen gas). The typical range of reaction conditions for wet oxidation are 150 to $320^{\circ} \mathrm{C}$ at 20 to 150 bar of pressure and a residence time of 15 to 120 minutes Zou et al. (2007). A historical review of wet oxidation for the treatment of pulpmill liquors and subsequently for wastewater sludge treatment over the last 40 years is given in Debellefontaine \& Foussard (2000).

Given that wet oxidation does not require water removal prior to treatment, it can directly process liquid municipal sludge. Furthermore the high temperatures involved kill the pathogens present and sterilise the material. While the wet oxidation process has been the focus of numerous studies Van Amstel \& Rietema (1973); Li et al. (1991); Mishra et al. (1995); Debellefontaine \& Foussard (2000), there are still relatively few models that describe the kinetic behaviour of the intermediate and final products of municipal sludge under different reaction conditions needed for an in-depth process analysis.

The first stage in the wet oxidation of sludge involves a large proportion of the insoluble organic content being solubilised through hydrolytic depolymerisation. Subsequent oxidative reactions convert these hydrolysis products into 
increasingly simpler organics such as acetic acid and formic acid, and acetone and ash. Finally these products can be further oxidised to $\mathrm{CO}_{2}$, water and residual ash, Bernardi et al. (2010); Debellefontaine \& Foussard (2000).

The reaction pathways that occur under wet oxidation are complex and poorly characterised. Even wet oxidation of pure substances such as phenol have been shown to decompose via numerous reaction pathways, and therefore it is necessary to use a simplified kinetic model which only includes the dominant reaction pathways Moreno et al. (2012); Zhang \& Chuang (1999). Because of this, simplified lumped kinetic models, often employing pseudo-components such as Chemical Oxygen Demand (COD) in the kinetic model, are used to conveniently describe the wet oxidation process.

The variety of previously proposed lumped parameter models for the wet oxidation of a range of waste products, (including municipal sludge) is evident from the range of models listed in Table 1. Van Amstel \& Rietema (1973) was one of the first to propose a lumped model for municipal sludge. This early work was further expanded by other researchers Foussard et al. (1989); Li et al. (1991); Khan et al. (1999); Shanableh (2004) who investigated different operating conditions and proposed modifications to the kinetic pathways. Li et al. (1991) proposed the familiar generalised lumped kinetic model for municipal sludge which forms the basis for the development of the kinetic model proposed in this work.

Historically, the primary outcome of wet oxidation applied to municipal waste was complete oxidation to the final end products which are mainly $\mathrm{CO}_{2}$, water and residual solids, Mishra et al. (1995). However with wastewater treatment plants incorporating Biological Nutrient Removal (BNR) facilities becoming more common, the short chain acids which are an intermediate product of wet oxidation, can be used as an effective carbon source for the denitrifying bacteria, Djafer et al. (2000); Shanableh \& Jomaa (2005); Strong et al. (2011); Andrews et al. (2014); Baroutian et al. (2015).

While models like that proposed by Li et al. (1991) give information on the rate of solids or COD reduction and acetic acid production, they generally lack 
Table 1: Summary of published wet oxidation kinetic models. (See also Table 2.)

\begin{tabular}{|c|c|c|c|c|}
\hline Investigators & $\begin{array}{l}\text { Feed } \\
\text { material }\end{array}$ & $\begin{array}{l}\text { Model } \\
\text { inputs }\end{array}$ & $\begin{array}{l}\text { Reaction } \\
\text { pathways }\end{array}$ & $\begin{array}{c}\text { Validated } \\
\text { states }\end{array}$ \\
\hline Takamatsu et al. (1970) & $\begin{array}{l}\text { Mixture of peptone, } \\
\text { glucose \& metal salts }\end{array}$ & $\mathrm{O}_{2}, \mathrm{~T}$ & 3 & 3 \\
\hline Van Amstel (1971) & Municipal sludge & $\mathrm{O}_{2}, \mathrm{~T}, \mathrm{P}$ & 2 & 1 \\
\hline Foussard et al. (1989) & Municipal sludge & $\mathrm{O}_{2}, \mathrm{~T}$ & 2 & 1 \\
\hline Li et al. (1991) & Municipal sludge & $\mathrm{O}_{2}, \mathrm{~T}$ & 3 & 1 \\
\hline Khan et al. (1999) & Municipal sludge & $\mathrm{O}_{2}, \mathrm{~T}$ & 4 & 4 \\
\hline Zhang \& Chuang (1999) & Kraft pulp sludge & $\mathrm{O}_{2}, \mathrm{~T}$ & 2 & 1 \\
\hline $\begin{array}{l}\text { Verenich \& Kallas (2002); } \\
\text { Verenich et al. (2003) }\end{array}$ & Pulp mill liquor & $\mathrm{O}_{2}, \mathrm{~T}$ & 4 & 1 \\
\hline Shanableh (2004) & Municipal sludge & $\mathrm{O}_{2}, \mathrm{~T}$ & 2 & 2 \\
\hline $\begin{array}{l}\text { Chacuk \& Imbierowicz } \\
(2007)\end{array}$ & Municipal sludge & $\mathrm{O}_{2}, \mathrm{~T}$ & 4 & 0 \\
\hline Mucha \& Zarzycki (2008) & Municipal sludge & $\mathrm{T}$ & 4 & 1 \\
\hline Bertanza et al. (2014) & Municipal sludge & $\mathrm{O}_{2}, \mathrm{~T}$ & 3 & 2 \\
\hline This work & Municipal sludge & $\mathrm{O}_{2}, \mathrm{~T}, \mathrm{P}, \mathrm{RPM}$ & 12 & 7 \\
\hline
\end{tabular}


detailed modelling of the intermediate products produced, such as the fate of nitrogen based compounds. The additional load of these intermediate products in the liquid effluent produced by a wet oxidation facility has the potential to upset downstream biological treatment processes. This provides the motivation to develop a more comprehensive model that can better predict the fate of these intermediate compounds.

Despite the fact that wet oxidation liquor is a useful supplement for a BNR treatment plant, and generalised kinetic models of wet oxidation are available, none of the dynamic models in Table 1 adequately describe the spectrum of intermediate products, and the conditions under which they are produced. Consequently there is a need for more detailed kinetic models describing wet oxidation which characterise sufficiently the concentrations of the intermediate compounds, such that potential impact on a downstream biological treatment plant can be predicted. Therefore, this paper proposes a detailed kinetic model for wet oxidation of municipal sludge which can predict the concentration of intermediate products which are important to BNR processes under different reaction conditions.

Table 2 compares the kinetic structure of the key lumped kinetic models noted in Table 1 starting with the basic Li et al. (1991) model similar to that presented in (Bertanza et al., 2014, Table 3). In all models, the variable $k_{i}$ is an Arrhenius based rate expression. The species symbols used are the same as the original references. In the models presented by Mucha \& Zarzycki (2008) and Bertanza et al. (2014), $S$ are the feedstock particular organic compounds, $L, L_{1}$ are intermediate liquid products, and $G_{i}$ and $L_{k}, L_{2}$ refers to gaseous and non biodegradable liquid products respectively. It is clear from the topology that while they may appear different, from a mechanistic viewpoint they are related, and descend from the Li et al model. Each model starts with an initial compound which is degraded or solubilised to an intermediate product. This is then oxidised to one or more reaction end products. For comparison, the model presented in this work is given in Fig. 3.

However there are some deficiencies of these mechanistic models which was 
Table 2: Comparison of published wet oxidation kinetic pathways.

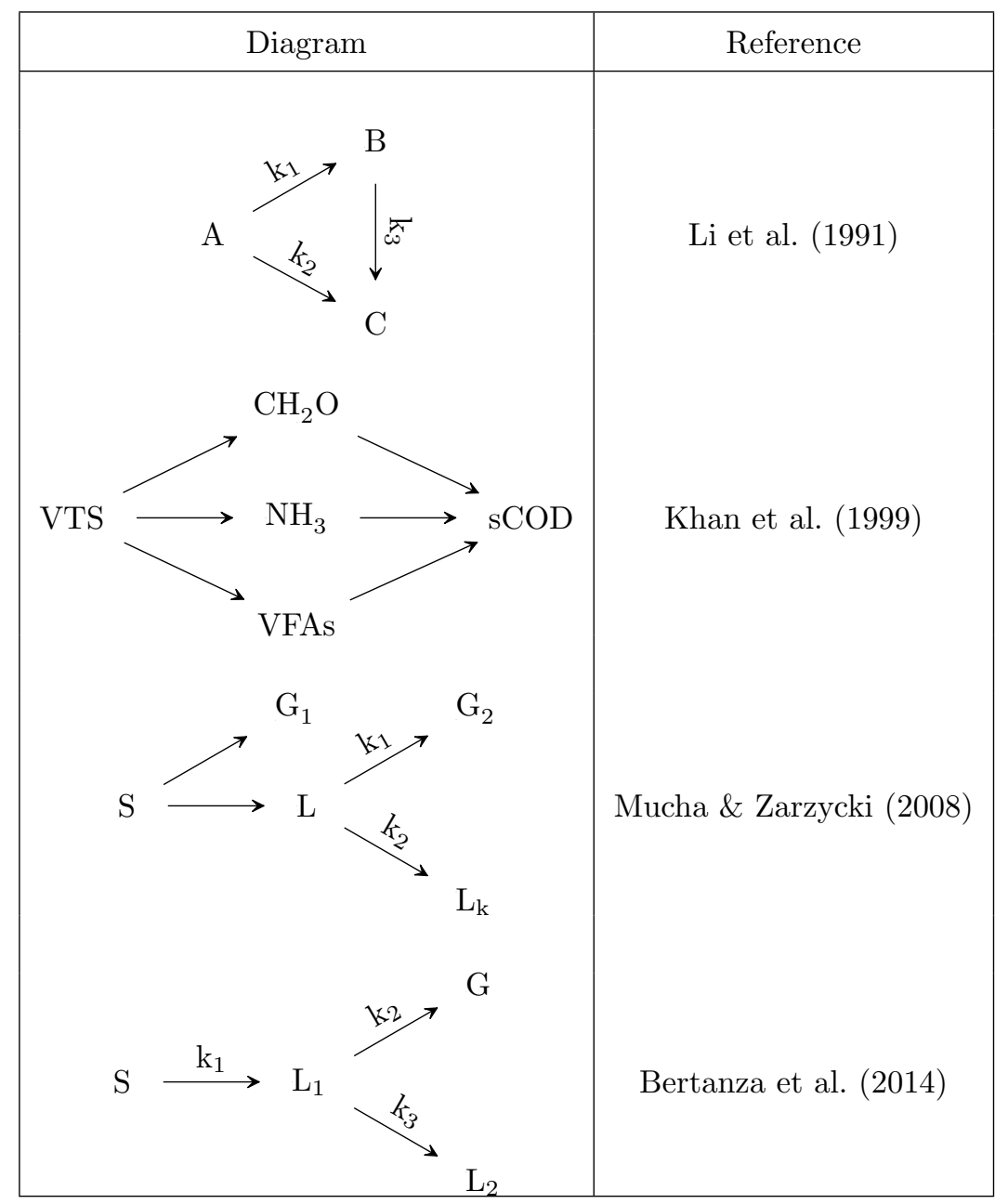


the motivating factor to develop a more comprehensive model and to undertake experiments to investigated the effect of temperature, oxygen partial pressure and mixing in the form of stirrer speed, on the degradation of biosolids under wet oxidation. The currently available kinetic models (such as those presented in Table 2) do not typically take into account the effect of all the operational parameters. Furthermore it was important to be able to track the nitrogenous species.

In summary, this paper's contribution is the development of a kinetic model based on the results of the lab scale experimental programme, to validate the model against pilot-plant data and to explore optimum operating points.

\section{Materials and Methods}

The municipal biosolids feed material used for the experiments was obtained from the Rotorua Lakes Council (RLC) wastewater treatment plant. Rotorua is a medium sized rural town of 70,000 and is typical of many municipalities in New Zealand. The biosolids consisted of approximately $40 \%$ primary and $60 \%$ secondary sludge obtained from the belt presses at the processing plant. The biosolids were subsequently fermented in a 2000L pilot plant anaerobic fermenter at $35^{\circ} \mathrm{C}$ under $\mathrm{pH}$ control of between 5.5 and 6.2. Samples of the fermented sludge were frozen at $-20^{\circ} \mathrm{C}$ until required. For this study, the following metrics were of particular interest: Total Suspended Solids (TSS), Volatile Suspended Solids (VSS), Total COD (tCOD), Particulate COD (pCOD), Soluble COD (sCOD), Acetic Acid COD (AACOD), Dissolved Organic Nitrogen (DON). The characteristics of the sludge used in the experiments are shown in Table 3.

For this study, experiments were performed on two wet oxidation systems: a laboratory scale stirred reactor used to develop and regress the dynamic model, and a pilot plant employing a 300L bubble column reactor used purely for validation. 
Table 3: Characteristics of the diluted municipal biosolids from the RLC wastewater treatment plant used for the experimental investigation.

\begin{tabular}{|l|c|}
\hline Characteristics & {$[\mathrm{mg} / \mathrm{L}]$} \\
\hline TSS & $14872 \pm 542$ \\
VSS & $12082 \pm 440$ \\
tCOD & $24720 \pm 901$ \\
pCOD & $17640 \pm 643$ \\
sCOD & $7080 \pm 258$ \\
Acetic acid & $1364 \pm 50$ \\
Propionic acid & $664 \pm 24$ \\
Iso-butyric acid & $143 \pm 5$ \\
N-butyric acid & $542 \pm 20$ \\
NH 4 & $470 \pm 10$ \\
DKN & $560 \pm 12$ \\
TC & $7000 \pm 100$ \\
TN & $1200 \pm 20$ \\
\hline
\end{tabular}




\subsection{Lab Scale Reactor Procedure}

Wet oxidation experiments were carried out in a Parr high pressure reactor (model \# 4540. Parr Instrument Company, USA) with model \# 4848 controller as described in Baroutian et al. (2015). The experimental system depicted in Fig. 1 was equipped with a pre-heated feed vessel in which $150 \mathrm{~mL}$ of sludge slurry was heated to $90^{\circ} \mathrm{C}$ for 5 minutes with stirring. This minimised the temperature differential associated when the sample was transferred to the reactor. In order reduce the possibility of hydrolysis reactions occurring during the heat up stage, the sludge was injected to the reactor only when the vessel had reached the desired temperature. This control system is PID controller with auto-tuning capability which is able to precisely control temperature with a minimum overshoot.

For each experiment the reactor was charged with $250 \mathrm{~mL}$ water and was initially pressurised with pure oxygen (20-40 bar) to obtain an oxygen to biomass ratios of $1: 1$ to $2: 1$. These ratios were calculated based on the stoichiometric oxidation potential using assumed biomass composition of $\mathrm{CH}_{1.8} \mathrm{O}_{0.5} \mathrm{~N}_{0.2}$. It was then heated to 220 to $240^{\circ} \mathrm{C}$ before the pre-heated sludge was introduced by means of pressure difference generated by nitrogen gas back pressure. After the injection of sludge, the initial concentration of solids in the reactor was approximately $1.5 \mathrm{wt} \%$. The experiments were carried out using stirring speeds ranging from 300 to 500 revolutions per minute (RPM) corresponding to power numbers, $P_{o}$, of 128 to 27 . The mixing was fully turbulent with the Reynolds number, $R e>10^{5}$. The use of RPM as a variable as opposed to Reynolds number or energy dissipation for describing turbulence is purely pragmatic since it is easier to measure. In any case, as will be evident in section 3, this variable had negligible effect on the model.

Using a manual extraction system, $20 \mathrm{~mL}$ liquid samples were taken after 2 , 5, 10, 20 and 60 minutes. The sampling tube was flushed with water followed by nitrogen gas after each sample was collected. Samples were cooled to room temperature immediately to stop further reaction. A total of 18 experiments were conducted following a fractional factorial design, exploring different com- 


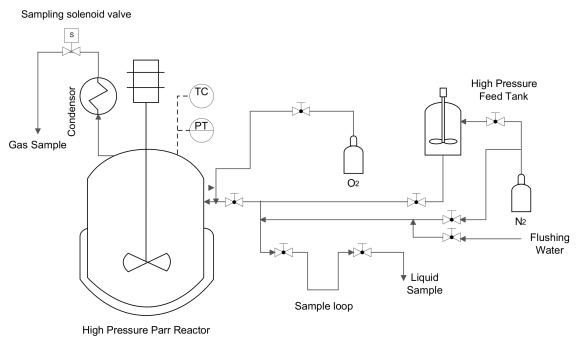

(a) Digram of lab scale Parr reactor

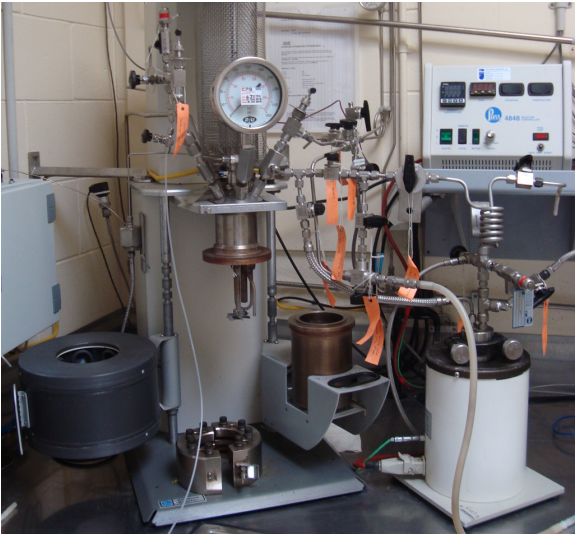

(b) Photograph of Parr reactor and sampling system

Figure 1: The bench-scale Parr reactor

Figure 2: The pilot plant reactor

binations of temperature, oxygen partial pressure and stirring speed with the center of the design space repeated 4 times.

Gas samples from the reactor headspace were taken for four of the experiments using a high pressure Valco selector valve, which directed the gas though a cooler, reducing the temperature of the samples to $10^{\circ} \mathrm{C}$. The gas samples of approximately $20 \mathrm{~mL}$ volume were collected in Tedlar gas sample bags for later analysis.

\subsection{Pilot Plant}

Wet oxidation experiments were performed on a semi-batch pilot plant facility to validate the results from the lab scale investigation, Andrews et al. (2015); Lei et al. (2013); Aggrey et al. (2011). The pilot plant, shown in Fig. 2 consists of a 300L bubble column reactor utilising co-current gas and liquid recirculation to promote mixing of the two phases.

An important difference in operating procedure between the bench-scale and pilot reactors was the requirement to use a continuous flow of oxygen in the pilot 
plant. PID control was used to maintain the oxygen concentration in the reactor headspace to between 20 and $25 \%$. It was not possible to operate the reactor in fully batch mode with pure oxygen in the reactor due to safety concerns. A second difference is that the laboratory reactor is mechanically stirred, while the pilot plant relies on gas recirculation to provide the mixing.

The feed tank was filled with municipal sludge which was the same source of feed material for the lab scale experiments. Water was added to dilute the feed to the required concentration of $1.5 \%$ solids. Approximately $150 \mathrm{~kg}$ of biosolids were then pumped into the main reactor, which was then pressurised to 20 bar using compressed air, and the heating and circulation systems were started. After the initial pressurisation, pure oxygen was used to maintain the oxygen concentration in the reactor to between 20 and $25 \%$.

After the temperature had reached the required setpoint, liquid samples of the reactor contents were taken approximately every 15 minutes and immediately quenched to stop further reactions, while the oxygen concentration was continuously sampled as part of the reactor control system. Other gasses apart from oxygen were not measured on the pilot plant due to equipment constraints.

\subsection{Analysis Procedure}

Liquid samples collected in this study were analysed for COD (total COD, soluble COD and particulate COD), solids (TSS and VSS), VFAs, $\mathrm{NH}_{4}$ and DKN (dissolved Kjeldahl nitrogen). The analysis procedure followed standard methods recommended by the American Public Health Association Anon (1998). The tCOD used in this work was calculated following the procedure by Baroutian et al. (2013) because of the large variability in the tCOD measurement. This discrepancy is suspected to be due to the inhomogeneous nature of the intermediate samples.

\subsection{Kinetic Modelling of Wet Oxidation}

A common family of intermediate compounds are produced during the wet oxidation process. These are primarily short chain volatile fatty acids and dissolved nitrogen in the form of ammonia. As mentioned in Section 1, the focus 
of this study was to develop kinetic models that characterise the degradation of sludge and the production of intermediate compounds. For this study, several COD based pseudo-compounds were postulated to characterise the behaviour observed from the experimental data, with many being common wastewater quality indicators and are shown in Table 4. This simplification is in line with previous work such as Li et al. (1991) and Zhang \& Chuang (1999).

For this study, the following pseudo-components were of particular interest, particulate COD (pCOD), soluble COD (sCOD), acetic acid (AACOD), volatile fatty acids (VFACOD), dissolved organic nitrogen (DON) and $\mathrm{CO}_{2}$.

Table 4: A summary of the measured and derived state variables in the extended model.

\begin{tabular}{|l|l|l|}
\hline State variables & Derived state variables & Measured states \\
\hline pCODfast & pCOD $=$ pCODfast+pCODslow & pCOD \\
pCODslow & sCOD $=$ sCODfast+sCODslow+sCODnr & sCOD \\
sCODfast & VFACOD=VFAfast+VFAslow & VFACOD \\
sCODslow & $\mathrm{O}_{2(\mathrm{aq})}$ & DON \\
sCODnr & & AACOD \\
AACOD & & $\mathrm{O}_{2(\mathrm{~g})}$ \\
VFACODfast & & $\mathrm{CO}_{2}$ \\
VFACODslow & & \\
DON & & \\
$\mathrm{O}_{2(\mathrm{~g})}$ & & \\
$\mathrm{CO}_{2}$ & & \\
\hline
\end{tabular}

Based on the results obtained from this experimental study, and the kinetic models available in the literature, a new set of 12 reaction pathways has been proposed. A lumping approach has been used and the reaction species are characterised in terms of their COD.

Like Shanableh (2004), the current study proposed that biosolids particles in the form of pCOD are first transformed into $\mathrm{SCOD}$, and it is the SCOD which is 
then oxidised into acetic acid, other VFA's, and a portion is oxidised directly to $\mathrm{CO}_{2}$. The VFACOD component accounts for all other VFAs such as propionic acid which were observed to degrade under the reaction conditions in this study.

The analysis of the experimental data revealed that pCOD and sCOD consisted of multiple fractions. This phenomena was also noted previously by Shanableh who denoted the fractions of pCOD and SCOD as difficult to degrade and easy to degrade.

In this study, pCOD and sCOD have been subdivided into fast reacting (CODf) and slow reacting (CODs) fractions, while sCOD also has a non-reacting remainder, (CODnr). These have thus been denoted as pCODf, pCODs, sCODf, sCODs and sCODnr in the reaction pathways. The fractions for pCOD and sCOD were regressed to fit the experimental data.

The following reaction pathways are proposed following the kinetic pathway given in Fig. 3 to describe wet oxidation of municipal sludge and are implemented as ordinary differential equations (ODEs) in the model.

Particulate COD first solubilises into soluble COD following reactions R1 and R2

$$
\begin{aligned}
& \text { pCODf } \stackrel{\mathrm{r}_{1}}{\longrightarrow} x \cdot \mathrm{sCODf}+y \cdot \mathrm{sCODs}+(1-x-y) \cdot \mathrm{sCODnr} \\
& \mathrm{pCODs} \stackrel{\mathrm{r}_{2}}{\longrightarrow} x \cdot \mathrm{sCODf}+y \cdot \mathrm{sCODs}+(1-x-y) \cdot \mathrm{sCODnr} .
\end{aligned}
$$

Particulate COD is assumed to hydrolyse into fast and slowly solubilising fractions, and the reactions are assumed not to consume oxygen. The nitrogen containing fraction of pCOD is assumed to solubilise to DON,

$$
\mathrm{pCODs} \stackrel{\mathrm{r}_{3}}{\longrightarrow} \mathrm{DON} \text {. }
$$


Figure 3: The kinetic pathway for the proposed model in this study. (See also Table 2 for previously proposed kinetic pathways.) 
Soluble COD then oxidises as shown in reactions R4 to R12

$$
\begin{aligned}
& \mathrm{sCODf}+\mathrm{O}_{2(\mathrm{aq})} \stackrel{\mathrm{r}_{4}}{\longrightarrow} \mathrm{CO}_{2} \quad[\mathrm{R} \text { 4] } \\
& \mathrm{sCODs}+\mathrm{O}_{2(\mathrm{aq})} \stackrel{\mathrm{r}_{5}}{\longrightarrow} \mathrm{CO}_{2} \quad[\mathrm{R} 5] \\
& \mathrm{sCODf}+\mathrm{O}_{2(\mathrm{aq})} \stackrel{\mathrm{r}_{6}}{\longrightarrow} \mathrm{AACOD} \quad[\mathrm{R} 6] \\
& \mathrm{sCODs}+\mathrm{O}_{2(\mathrm{aq})} \stackrel{\mathrm{r}_{7}}{\longrightarrow} \mathrm{AACOD} \quad[\mathrm{R} 7] \\
& \mathrm{sCODf}+\mathrm{O}_{2(\mathrm{aq})} \stackrel{\mathrm{r}_{8}}{\longrightarrow} j \cdot \text { VFACODf }+(1-j) \cdot \text { VFACODs } \quad[\mathrm{R} 8] \\
& \mathrm{sCODs}+\mathrm{O}_{2(\mathrm{aq})} \stackrel{\mathrm{r}_{9}}{\longrightarrow} j \cdot \mathrm{VFACODf}+(1-j) \cdot \text { VFACODs } \quad[\mathrm{R} 9] \\
& \mathrm{VFACODf}+\mathrm{O}_{2(\mathrm{aq})} \stackrel{\mathrm{r}_{10}}{\longrightarrow} \mathrm{CO}_{2} \quad \text { [R 10] } \\
& \text { VFACODs }+\mathrm{O}_{2(\mathrm{aq})} \stackrel{\mathrm{r}_{11}}{\longrightarrow} \mathrm{CO}_{2} \quad \text { [R 11] } \\
& \mathrm{DON}+\mathrm{O}_{2(\mathrm{aq})} \stackrel{\mathrm{r}_{12}}{\longrightarrow} \mathrm{NH}_{4} \quad[\mathrm{R} 12]
\end{aligned}
$$

These reactions are subject to the following algebraic mass constraints

$$
\begin{aligned}
\mathrm{sCOD} & =\mathrm{sCODf}+\mathrm{sCODs}+\mathrm{sCODnr} \\
\mathrm{pCOD} & =\mathrm{pCODf}+\mathrm{pCODs} \\
\mathrm{VFACOD} & =\text { VFACODf }+ \text { VFACODs } \\
1 & =x+y, \quad(x, y>0) \\
0 & <j<1
\end{aligned}
$$

where $x, y$ and $z$ are the fractions of fast reacting, slow reacting and nonreactive soluble COD, and $j$ are the fractions of fast and slowly reacting VFA. The reaction rate $r$ in reactions $\mathrm{R} 1$ to $\mathrm{R} 12$ is assumed of the form

$$
r_{i}=[\mathrm{C}]\left[\mathrm{O}_{2(\mathrm{aq})}\right]^{n} k_{i} \exp \left(\frac{-E_{a}}{R T}\right) \mathrm{N}^{c}
$$

${ }_{225}$ Where $[\mathrm{C}]$ and $\left[\mathrm{O}_{2(\mathrm{aq})}\right]$ are the reactant and oxygen concentrations, $n$ is the reac-

226 tion order with respect to oxygen, $k_{i}$ is the rate constant (in variable units), $E_{a}$ is

${ }_{227}$ the activation energy $\left(\mathrm{Jmol}^{-1}\right), R$ is the ideal gas constant $\left(8.3145 \mathrm{JK}^{-1} \mathrm{~mol}^{-1}\right)$,

${ }_{228} T$ is temperature (Kelvin), $\mathrm{N}$ is the stirrer speed (RPM) and $c$ is the mixing 
constant (dimensionless). The kinetic equation is based on the work of Li et al. (1991); Debellefontaine \& Foussard (2000). The effect of oxygen has been in cluded for all reactions, except the solubilisation of pCOD, to attempt to account for other un-modelled reaction pathways or effects that may be occurring. Further simplifications include no gas-liquid mass transfer limitations and the reactant order was hard-coded as 1 following the work of Li et al. (1991).

Reactions R 3 and R 12 deserve some comment. While the formation of ammoniacal nitrogen is not modelled with strict mechanistically accuracy, these reactions allow the tracking of nitrogenous species conversion. This approach was justified by the fact that the DON measurement itself is not describing a molecule, but the presence of an element within a group of unknown compounds, these latter contributing to the overall substrate COD. In this work, we attributed the nitrogen containing COD to the slowly degradable particulate fraction.

The effect of stirrer speed changes was accounted for by a power law based on the work of Meille et al. (2004) who demonstrated that it adequately captured the effects of the change in stirrer speed. Henry's law was used internally in the model to predict the concentration of dissolved oxygen based on the current operating conditions, Himmelblau (1960).

The act of sampling was accounted for as part of the reactor model developed in this study because of the moderate change in liquid volume during the course of the experiments as the result of sampling.

\subsection{Parameter Regression}

The kinetic model developed in the previous section consists of a total of 12 reactions, 11 states, 3 derived states, and a number of other parameters which need to be fitted. Each reaction has a total of 4 free parameters.

In order to have sufficient fitting data, the data from all experiments performed on the lab scale reactor for this study was used and fitted simultaneously. This results in a total of 266 ordinary differential equations, and 52 free parameters. The number of equations is primarily a function of how many experiments 
were carried out, and the number of parameters stems from the complexity of the model. Notwithstanding the problem is over defined.

The resultant nonlinear dynamic regression problem was solved using are solved using LN_COBYLA algorithm from the nlopt package which is part of the Opti toolbox, Currie \& Wilson (2012); Currie (2014) within the Matlab environment, taking around 4 hours to complete on a modern desktop computer. Given that this regression problem is both nonlinear and of high dimension, there is both the problem of local minima and that the parameters in the Arrhenius expression could easily be correlated meaning that the response contours are highly elliptical. It is impractical to completely remove these two problems, but they can be mitigated by scaling the regression problem prior to the optimisation, and by carefully choosing the initial guesses of the fitted variables, and subsequently repeating the optimisation from different starting points to avoid local minima. All three approaches were taken in this study.

Further details on the regression algorithm, starting conditions and convergence criteria are given in Prince-Pike (2014).

An increased weighting has been applied to the final $t=60$ value of $\mathrm{pCOD}$ to further improve the fit because of the large range between the initial and final pCOD concentrations. The confidence limits of the fitted parameters can be approximated using a linearised analysis following the strategy given in section 6.4 of Himmelblau (1970). The final values of the fitted kinetic parameters along with $95 \%$ confidence limits are presented in the following section.

\section{Results and Discussion}

To adequately cover the variable space, a fractional factorial experimental design was used as described in Prince-Pike (2014). Of the 18 experiments undertaken for this study, Figures 4 to 5 compare the model prediction against measured data for the components of interest for a subset of four different sets of reaction conditions. In these plots, the points indicate the experimentally measured concentrations while the curves show the regressed model predictions. 
The values and uncertainty limits of the model parameter values (parameters in the kinetics equations, and initial fractions of the compounds) are given in Table 5 .

The results in Figure 4 show the change in total, particulate and suspended COD (tCOD, pCOD and sCOD) over 60 minutes for four different scenarios, and the corresponding model predictions. The $\mathrm{O}_{2}$ content listed is based on the amount of initial pure oxygen in the reactor. The final COD removal rates of between 53 and $61 \%$ obtained in this experiment agrees with similar studies, Chung et al. (2009); Lendormi et al. (2001); Shanableh (2004) as does the particulate COD removal previously reported by Shanableh (2004). The error bars show that there is greater uncertainty in the early samples due to the inhomogeneous nature of the early samples, hence the justification to preferentially weight the later samples, particularly the final measured value which was known to a higher relative accuracy. Although the peak sCOD values are marginally higher in this work, the trend of sCOD evolution during the experiments was similar to Chung et al. (2009).

Figure 5 shows the change in AACOD and VFACOD for the same reaction conditions. While there is more variation in the results compared to pCOD and sCOD, the model still fits the data, however the fit for the early samples at 2 and 5 minutes is not as good. Apart from this discrepancy, the trend for AACOD and VFA degradation follows published results by Chung et al. (2009).

\subsection{A Statistical Assessment of Model Quality}

Given that the proposed model has more fitted parameters than previously proposed models, it is prudent to test if the extra complication is statistically justified. Table 5 lists all the fitted parameters and their associated $95 \%$ confidence limits. The fact that none of the parameter uncertainties span across zero gives an indication that all parameters are deemed statistically significant. With the exception of one parameter, $k_{0}$ for Reaction 5 at $44 \%$, all uncertainties are less than $30 \%$ of the nominal value. The confidence limits were not calculated 

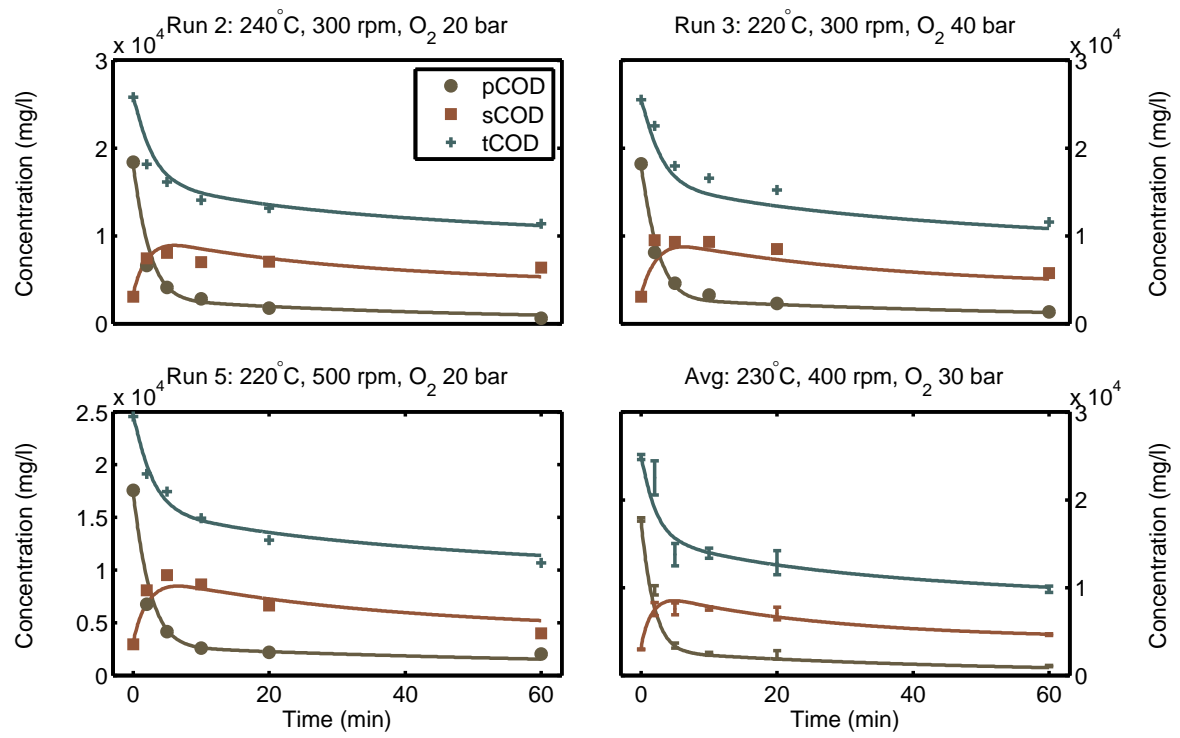

Figure 4: The concentration of particulate, suspended and total COD compared to model predictions during wet oxidation at four sets of reaction conditions.
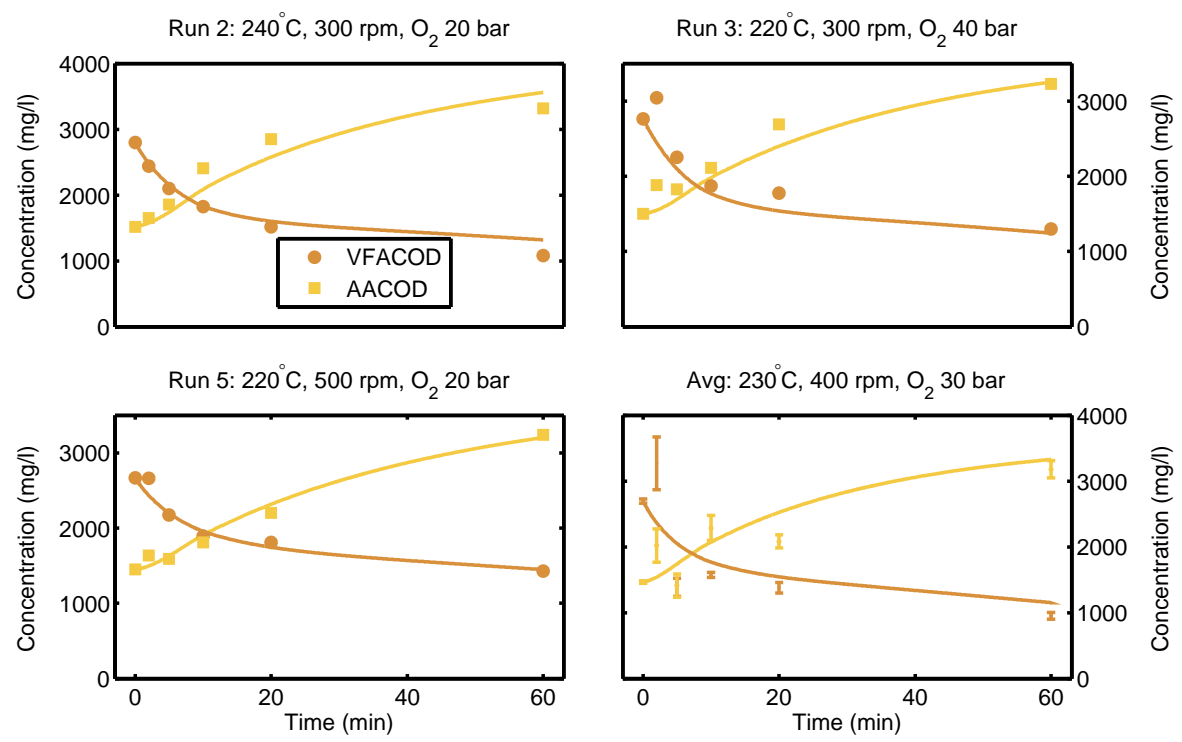

Figure 5: The concentration of AACOD and VFACOD during wet oxidation at four sets of reaction conditions. 

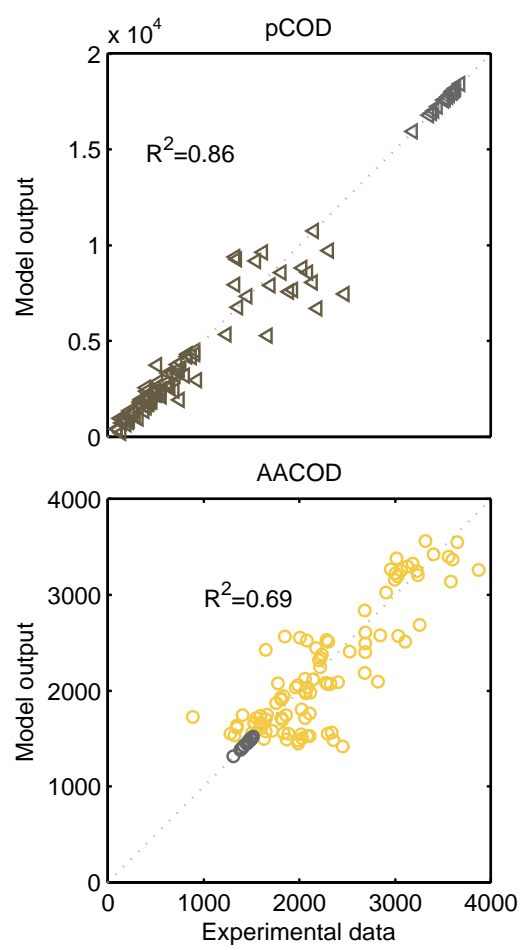
the parameter fitting.

or Reaction 8 because of the limited involvement at these reaction conditions, as such it was not included to reduce the number of parameters used.

The correlations for the main components of interest between the model predictions and actual measurements are given separately in Figure 6 for the important variables. In this case the initial conditions are shaded grey and are not included in the calculation for the individual correlation coefficient, $r^{2}$, noted in the subfigures because they were explicitly used as initial conditions in
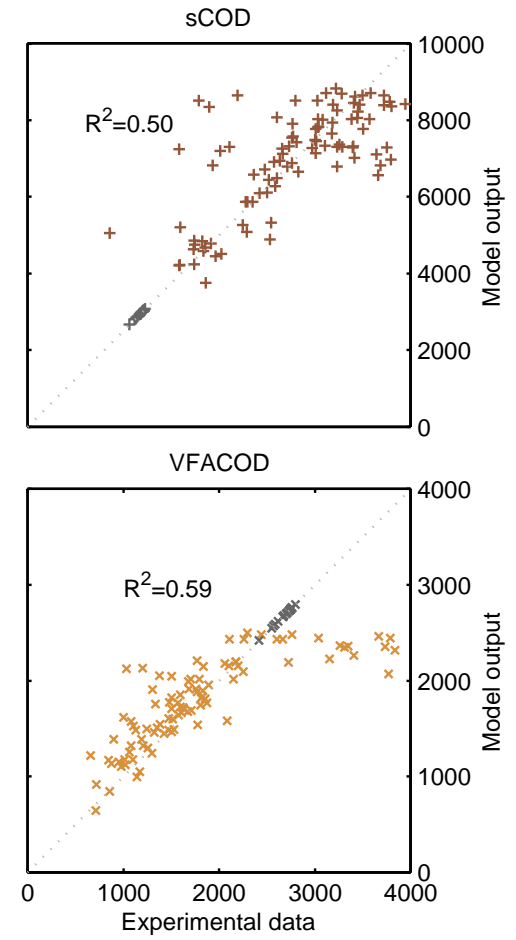

Figure 6: The correlation between model and experiment for the key individual components from the lab scale experiments.

The ANOVA analysis in Table 5 shows that all of the 47 parameters tested were significantly different from zero, indicated by the $t$ values being non-zero, and that the parameters were statistically significant as all $p$ values were much smaller than the value of 0.05 corresponding to the $95 \%$ confidence limit chosen 
330

Table 5: The fitted model parameters, their associated 95\% confidence limits and statistical 331

\begin{tabular}{|cc|l|l|c|l|}
\hline Reaction & & $\theta$ at $95 \%$ & Std error & $t$ value & $p$ value \\
\hline Rxn 1 & $k$ & $(1.78 \pm 0.46) \times 10^{3}$ & $2.35 \times 10^{2}$ & 7.59 & $1.82 \times 10^{-13}$ \\
& $E_{a}$ & $(4.03 \pm 0.40) \times 10^{4}$ & $1.90 \times 10^{3}$ & 21.26 & $7.49 \times 10^{-70}$ \\
& $n$ & $0.30 \pm 0.10$ & 0.05 & 6.23 & $1.10 \times 10^{-9}$ \\
& $c$ & $0.47 \pm 0.10$ & 0.05 & 9.22 & $1.16 \times 10^{-18}$ \\
\hline Rxn 2 & $k$ & $(3.08 \pm 0.96) \times 10^{6}$ & $4.89 \times 10^{5}$ & .30 & $7.31 \times 10^{-10}$ \\
& $E_{a}$ & $(1.25 \pm 0.08) \times 10^{5}$ & $4.28 \times 10^{3}$ & 29.18 & $1.16 \times 10^{-105}$ \\
& $n$ & $0.45 \pm 0.13$ & 0.07 & 6.57 & $1.40 \times 10^{-10}$ \\
& $c$ & $0.74 \pm 0.31$ & 0.16 & 4.59 & $5.66 \times 10^{-6}$ \\
\hline Rxn 3 & $k$ & $(5.91 \pm 2.18) \times 10^{2}$ & $1.11 \times 10^{2}$ & 5.33 & $1.56 \times 10^{-7}$ \\
& $E_{a}$ & $(4.88 \pm 0.59) \times 10^{4}$ & $2.99 \times 10^{2}$ & 16.33 & $2.25 \times 10^{-47}$ \\
& $n$ & $0.56 \pm 0.17$ & 0.09 & 6.44 & $3.04 \times 10^{-10}$ \\
& $c$ & $0.06 \pm 0.02$ & 0.01 & 5.01 & $7.86 \times 10^{-7}$ \\
\hline Rxn 4 & $k$ & $(1.76 \pm 0.49) \times 10^{3}$ & $2.49 \times 10^{2}$ & 7.09 & $5.38 \times 10^{-12}$ \\
& $E_{a}$ & $(3.53 \pm 0.40) \times 10^{4}$ & $2.03 \times 10^{3}$ & 17.37 & $4.78 \times 10^{-52}$ \\
& $n$ & $0.30 \pm 0.08$ & 0.04 & 7.31 & $1.26 \times 10^{-12}$ \\
& $c$ & $0.47 \pm 0.11$ & 0.06 & 8.45 & $4.18 \times 10^{-16}$ \\
\hline Rxn 5 & $k$ & $(3.87 \pm 1.73) \times 10^{5}$ & $8.81 \times 10^{4}$ & 4.40 & $1.36 \times 10^{-5}$ \\
\hline & & \multicolumn{3}{|l}{ Continued on next page } \\
\hline
\end{tabular}


Table 5 - continued from previous page

\begin{tabular}{|c|c|c|c|c|c|}
\hline \multicolumn{2}{|l|}{ Reaction } & $\theta$ at $95 \%$ & Std error & $t$ value & $p$ value \\
\hline & $E_{a}$ & $(1.07 \pm 0.08) \times 10^{5}$ & $3.93 \times 10^{3}$ & 27.26 & $3.65 \times 10^{-97}$ \\
\hline & $n$ & $0.93 \pm 0.30$ & 0.15 & 6.03 & $3.35 \times 10^{-9}$ \\
\hline & $c$ & $1.18 \pm 0.26$ & 0.13 & 8.94 & $1.02 \times 10^{-17}$ \\
\hline Rxn 6 & $k$ & $(7.40 \pm 1.83) \times 10^{2}$ & $9.31 \times 10^{1}$ & 7.94 & $1.62 \times 10^{-14}$ \\
\hline & $E_{a}$ & $(6.04 \pm 0.68) \times 10^{4}$ & $3.44 \times 10^{3}$ & 17.55 & $7.56 \times 10^{-53}$ \\
\hline & $n$ & $0.89 \pm 0.23$ & 0.12 & 7.57 & $2.18 \times 10^{-13}$ \\
\hline & $c$ & $0.55 \pm 0.14$ & 0.07 & 7.88 & $2.47 \times 10^{-14}$ \\
\hline Rxn 7 & $k$ & $(2.91 \pm 0.87) \times 10^{2}$ & $4.43 \times 10^{1}$ & 6.57 & $1.41 \times 10^{-10}$ \\
\hline & $E_{a}$ & $(4.79 \pm 0.54) \times 10^{4}$ & $2.75 \times 10^{3}$ & 17.44 & $2.41 \times 10^{-52}$ \\
\hline & $n$ & $0.25 \pm 0.09$ & 0.04 & 5.66 & $2.70 \times 10^{-8}$ \\
\hline & $c$ & $0.46 \pm 0.13$ & 0.07 & 6.84 & $2.61 \times 10^{-11}$ \\
\hline Rxn 8 & $k$ & $1.64 \times 10^{0}$ & - & - & - \\
\hline & $E_{a}$ & $1.84 \times 10^{5}$ & - & - & - \\
\hline & $n$ & 0.13 & - & - & - \\
\hline & $c$ & 0.02 & - & - & - \\
\hline Rxn 9 & $k$ & $(1.26 \pm 0.36) \times 10^{1}$ & 0.02 & 6.91 & $1.69 \times 10^{-11}$ \\
\hline & $E_{a}$ & $(3.76 \pm 0.60) \times 10^{4}$ & $3.03 \times 10^{2}$ & 12.42 & $1.27 \times 10^{-30}$ \\
\hline & $n$ & $0.31 \pm 0.10$ & 0.05 & 5.97 & $4.89 \times 10^{-9}$ \\
\hline & $c$ & $0.55 \pm 0.22$ & 0.11 & 4.84 & $1.77 \times 10^{-6}$ \\
\hline Rxn 10 & $k$ & $(8.42 \pm 3.3) \times 10^{2}$ & $1.66 \times 10^{2}$ & 5.09 & $5.39 \times 10^{-7}$ \\
\hline & $E_{a}$ & $(3.52 \pm 0.41) \times 10^{4}$ & $2.06 \times 10^{3}$ & 17.07 & $1.07 \times 10^{-50}$ \\
\hline
\end{tabular}


Table 5 - concluded from previous page

\begin{tabular}{|c|c|c|c|c|c|}
\hline \multicolumn{2}{|l|}{ Reaction } & $\theta$ at $95 \%$ & Std error & $t$ value & $p$ value \\
\hline \multirow{2}{*}{\multicolumn{2}{|c|}{$n$}} & $0.37 \pm 0.14$ & 0.07 & 5.23 & $2.63 \times 10^{-7}$ \\
\hline & & $0.06 \pm 0.03$ & 0.02 & 3.49 & $5.33 \times 10^{-4}$ \\
\hline \multirow[t]{4}{*}{ Rxn 11} & $k$ & $(9.67 \pm 3.30) \times 10^{1}$ & $1.67 \times 10^{1}$ & 5.82 & $1.10 \times 10^{-8}$ \\
\hline & $E_{a}$ & $(4.36 \pm 0.76) \times 10^{4}$ & $3.88 \times 10^{3}$ & 11.25 & $5.08 \times 10^{-26}$ \\
\hline & $n$ & $0.34 \pm 0.21$ & 0.11 & 3.22 & $1.37 \times 10^{-3}$ \\
\hline & $c$ & $0.40 \pm 0.13$ & 0.07 & 6.03 & $3.49 \times 10^{-9}$ \\
\hline \multirow[t]{4}{*}{$\operatorname{Rxn} 12$} & $k$ & $(1.21 \pm 0.44) \times 10^{1}$ & 2.27 & 5.34 & $1.48 \times 10^{-10}$ \\
\hline & $E_{a}$ & $(3.06 \pm 0.68) \times 10^{4}$ & $3.47 \times 10^{3}$ & 8.82 & $2.55 \times 10^{-17}$ \\
\hline & $n$ & $0.79 \pm 0.26$ & 0.13 & 5.93 & $5.96 \times 10^{-9}$ \\
\hline & $c$ & $0.17 \pm 0.07 \times 10^{-2}$ & $3.63 \times 10^{-4}$ & 4.66 & $4.26 \times 10^{-6}$ \\
\hline \multicolumn{6}{|c|}{ Initial conditions for state variables } \\
\hline \multicolumn{2}{|c|}{ pCOD fast } & 0.84 & & & \\
\hline \multicolumn{2}{|l|}{ pCOD slow } & 0.16 & & & \\
\hline \multicolumn{2}{|l|}{ sCOD fast } & $0.5 \pm 0.05$ & 0.02 & 21.6 & $7.30 \times 10^{-70}$ \\
\hline \multicolumn{2}{|l|}{ sCOD slow } & $0.30 \pm 0.05$ & 0.03 & 11.46 & $7.42 \times 10^{-27}$ \\
\hline \multicolumn{2}{|l|}{ sCOD nr } & 0.20 & & & \\
\hline \multicolumn{2}{|l|}{ VFACOD fast } & $0.49 \pm 0.11$ & 0.06 & 8.60 & $1.39 \times 10^{-16}$ \\
\hline \multicolumn{2}{|l|}{ VFACOD slow } & 0.51 & & & \\
\hline
\end{tabular}

The extremely small $p$ value for the ANOVA summary in Table 6 demonstrates that it is highly unlikely that all model coefficients are zero.

Table 7 gives the overall fit of the extended kinetic model. The high values for $R^{2}$ and the adjusted $R^{2}$ show that the model is able to describe the variation observed in the experimental data with a reasonable level of accuracy. The actual values of the sum of squared errors, and the root-mean-square error are scale dependent, (so difficult to compare in general sense) but are commonly stated in an analysis of variance.

Overall, the model is shown to predict the likely concentrations of the components of interest with a good level of accuracy, given the variation in the experi- 
Table 6: Nonlinear least-squares analysis of variance.

\begin{tabular}{|l|c|c|c|c|c|}
\hline Source & $\begin{array}{c}\text { Degrees } \\
\text { of Freedom }\end{array}$ & $\begin{array}{c}\text { Sum } \\
\text { of Squares }\end{array}$ & Mean Square & $F$ Value & $p$ Value \\
\hline Model & 47 & $9.09 \times 10^{9}$ & $1.93 \times 10^{8}$ & 244 & $1.28 \times 10^{-288}$ \\
Error & 448 & $3.95 \times 10^{8}$ & $8.82 \times 10^{5}$ & & \\
Corrected & 495 & $9.49 \times 10^{9}$ & & & \\
total & & & & & \\
\hline
\end{tabular}

Table 7: Overall model fit.

\begin{tabular}{|l|c|}
\hline Statistical metric & Value \\
\hline$R^{2}$ & 0.925 \\
Adjusted $R^{2}$ & 0.917 \\
SSE & $3.953 \times 10^{8}$ \\
RMSE & 939.375 \\
\hline
\end{tabular}


mental data used for regression. The above statistical analysis has demonstrated that the model is statistically valid, and all the fitted model parameters are statistically significant. This suggests that the model is not over-parametrised, despite the large number of parameters.

The regressed model constants in Table 5 are of the same order of magnitude as that reported by Shanableh (2004) who determined the kinetic parameters for particulate COD degradation (both slow and fast) to be $k_{0}=9.61 \times 10^{3} \mathrm{~s}^{-1}$ and $E_{a}=8.65 \times 10^{4} \mathrm{~J} \cdot \mathrm{mol}^{-1}$ compared to the values regressed in this study of $k_{0}=1.78 \times 10^{3} \mathrm{~s}^{-1}$ and $E_{a}=4.03 \times 10^{4} \mathrm{~J} \cdot \mathrm{mol}^{-1}$ for pCOD fast, with $k_{0}=3.08 \times 10^{6} \mathrm{~s}^{-1}$ and $E_{a}=1.25 \times 10^{5} \mathrm{~J} \cdot \mathrm{mol}^{-1}$ for pCOD slow. Values of the degradation of total COD from the triangular model of Li et al. (1991) in Table 2 are $k_{0}=1.2 \times 10^{4} \mathrm{~s}^{-1}$ and $E_{a}=6.70 \times 10^{4} \mathrm{~J} \cdot \mathrm{mol}^{-1}$ which are also in the same order of magnitude to those in the proposed model.

\subsection{Pilot Plant Validation Study}

To validate the proposed kinetic model, experiments were conducted on the wet oxidation pilot plant described in Section 2. Experimental data from a semi-batch experiment were then compared to the model predictions in Figure 7. It is important to note that the model used the kinetic parameters (shown in Table 5) regressed from the earlier lab scale experiments and was not re-fitted to the new data. The units of the gas trends plotted in Fig. 7 is the mass of gas $\left(\mathrm{CO}_{2}\right.$ or $\left.\mathrm{O}_{2}\right)$ remaining in the reactor at time $t$. Given that the pilot plant did not have a stirrer, an average value of 400 for the RPM was chosen although comparisons using neighbouring values of 300 and 500 showed only a small degradation to the overall predictive performance.

There were several practical sampling problems encountered during the experiment (which are noted in the subfigures), along with several outliers. Notwithstanding, Fig. 7 shows that the model predicts the concentrations for each of the measured components with a good level of accuracy. This provides confidence that the model structure and specific kinetic parameters di provide an adequate description of the wet oxidation of this particular organic biomass. 

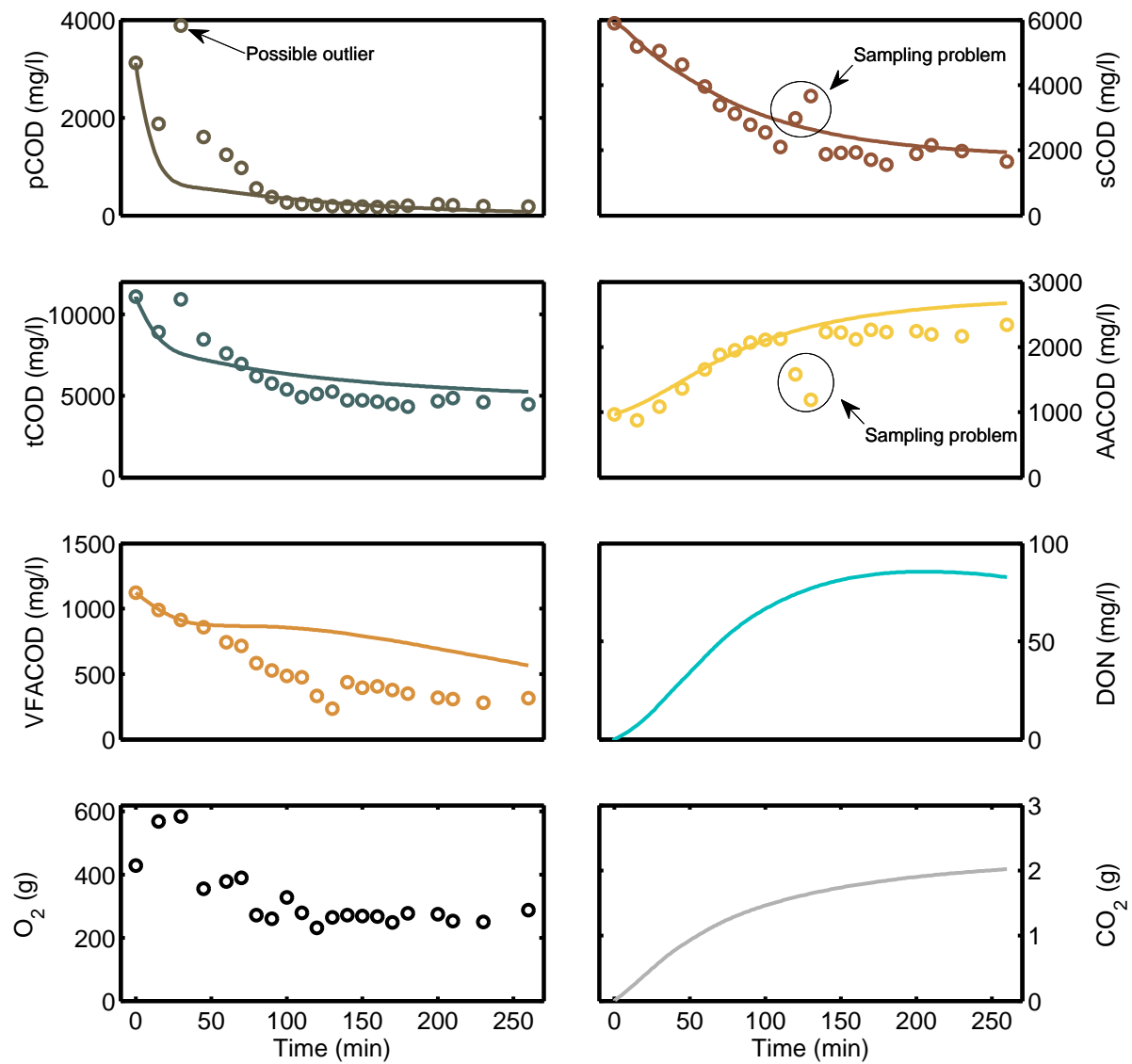

Figure 7: The kinetic model compared with a semi-batch pilot plant experiment. 


\subsection{Establishing an Optimum Operating Point}

One advantage of the dynamic kinetic model developed in this study is that it can be used for "what if" studies to investigate the effects of different processing conditions, and in fact this was one of the primary motivations for the study. For example, if the production aim was to produce both acetic acid and other VFAs for use in a downstream BNR wastewater treatment plant, this would require that the total VFA and acetic acid concentration is maximised. The complication arises because these two components of the objective function are competing.

Figure 8 shows the prediction of the concentration for the acetic acid, the VFA and the total acetic plus VFA (in the columns) after $30 \mathrm{~min}, 1$ hour and 2 hours (in the rows) for different operating temperatures and oxygen partial pressures. Note that both the plotted temperature range (from $210^{\circ} \mathrm{C}$ to $260^{\circ} \mathrm{C}$ ) and the plotted oxygen partial pressure range (from 20 to 60 bar) is deliberately extrapolated outside the ranges used during the experiments. (The experimental points for comparison are shown as the dashed rectangle in plot (g) of Fig. 8.) The performance curves in Fig. 8 show that longer batch times deliver a higher yield (not unexpectedly), but that the maximum is gained at lower temperatures. The results also suggest that one should operate at low concentrations of oxygen, but of course there is a limit given that there must be sufficient oxygen present to prevent excessive carbon monoxide production through incomplete oxidative conversion. Finally, the differences in the contour shapes at all times between the acetic acid production, which favours high operating temperatures, and the production of VFAs which favour low temperatures is immediately evident.

Figure 8: The concentration of acetic acid, VFA and the combination (in columns) as predicted from the model at different reaction times (in rows) for a range of operating temperatures and pressures. Contour lines show the concentration on a mg/L COD basis and points in plot $(\mathrm{g})$ show where the experiments were undertaken.

This representative operation optimisation illustrates the ability of using a 
dynamic model to highlight optimum operating points which are not always obvious because of the requirement to maximise acetic acid and maximise VFAs which are competing objectives. However it should be noted that the performance in a continuous reactor may be different.

\section{Conclusion}

This paper proposes a dynamic model for wet oxidation of municipal sludge. While this model is more complex than alternative models, it was shown to agree closely with the concentration results obtained from the experimental investigation. The model contains a number of simplifications to reduce complexity and the results suggest that, despite these simplifications, the model still accurately captures the effects of wet oxidation. Notwithstanding, the dynamic model is reasonably complex comprising of 52 parameters and a minimum of 12 dynamic equations depending on the amount of experimental data. A statistical analysis of the linearised model indicated that 47 fitted parameters were statistically significant. The effect of temperature, oxygen partial pressure and stirring speed were investigated and the effects that these parameters have on each of the model components has been captured in the developed kinetic model.

Applying the proposed kinetic model regressed at lab-scale to subsequently collected experimental data from a pilot-scale wet oxidation plant gave excellent agreement across the modelled components over the environmental conditions investigated. This validation step indicates that the reaction kinetics have been adequately captured as part of the kinetic model and strongly suggests that the model is likely to be useful at multiple scales.

\section{Acknowledgements}

The authors would like to acknowledge the financial support of Scion for the first author and would like to acknowledge the support of the Rotorua Lakes Council. 


\section{References}

Aggrey, A., Baroutian, S., \& Gapes, D. (2011). Wet Oxidation of Municipal Biosolids: Scions Terax process compared to European practices. In SCENZIChemE annual conference in New Zealand. Hamilton, NZ.

Andrews, J., Dare, P., Estcourt, G., Gapes, D., Lei, R., McDonald, B., \& Wijaya, N. (2015). Acetic acid recovery from a hybrid biologicalhydrothermal treatment process of sewage sludge - a pilot plant study. Water Science $\mathcal{E}$ Technology, 71, 734-739. doi:http://dx.doi.org/10.2166/wst.2015.021.

Andrews, J., Smit, A.-M., Wijeyekoon, S., McDonald, B., Baroutian, S., \& Gapes, D. (2014). Application of hydrothermal treatment to affect the fermentability of pinus radiata pulp mill effluent sludge. Bioresource Technology, 170, 100 - 107. URL: http://www.sciencedirect. com/science/article/pii/S0960852414010177. doi:http://dx.doi.org/ $10.1016 / j$. biortech. 2014.07.037.

Anon (1998). Standard Methods for the Examiniation of Water and Wastewater. Technical Report American Public Health Association, American Water Works Association, Water Environment Federation. 20th ed.

Baroutian, S., Smit, A.-M., Andrews, J., Young, B., \& Gapes, D. (2015). Hydrothermal degradation of organic matter in municipal sludge using non-catalytic wet oxidation. Chemical Engineering Journal, 260, 846-854. URL: http://www.sciencedirect. com/science/article/pii/S1385894714012595. doi:http://dx.doi.org/ $10.1016 / j$.cej.2014.09.063.

Baroutian, S., Smit, A.-M., \& Gapes, D. J. (2013). Relative influence of process variables during non-catalytic wet oxidation of municipal sludge. Bioresource Technology, (pp. 605-610). URL: http://www.sciencedirect. com/science/article/pii/S0960852413014181. doi:http://dx.doi.org/ 10.1016/j. biortech. 2013.08.160. 
Bernardi, M., Cretenot, D., Deleris, S., Descorme, C., Chauzy, J., \& Besson, M. (2010). Performances of soluble metallic salts in the catalytic wet air oxidation of sewage sludge. Catalysis Today, 15\%, 420 - 424. URL: http: //www.sciencedirect.com/science/article/pii/S0920586110000362. doi:http://dx.doi.org/10.1016/j.cattod.2010.01.030. 6th World Congress on Oxidation Catalysis Lille, France, 5-10 July 2009 Towards an integrated approach in innovation and development.

Bertanza, G., Galessi, R., Menoni, L., Salvetti, R., Slavik, E., \& Zanaboni, S. (2014). Wet oxidation of sewage sludge: full-scale experience and process modelling. Environmental Science and Pollution Research, (pp. 1-11). URL: http://dx.doi.org/10.1007/s11356-014-3144-9. doi:10 . 1007/s11356-014-3144-9.

Chacuk, A., \& Imbierowicz, M. (2007). Mathematical modelling of wet oxidation of excess sludge. Polish Journal of Chemical Technology, 9, 1-4.

Chung, J., Lee, M., Ahn, J., Bae, W., Lee, Y.-W., \& Shim, H. (2009). Effects of operational conditions on sludge degradation and organic acids formation in low-critical wet air oxidation. Journal of Hazardous Materials, 162, 10-16.

Currie, J. (2014). Practical Applications of Industrial Optimization: From highspeed embedded controllers to large discrete utility systems. Ph.D. thesis Auckland University of Technology Auckland, New Zealand.

Currie, J., \& Wilson, D. I. (2012). Opti: Lowering the Barrier Between Open Source Optimizers and the Industrial MATLAB User. In N. Sahinidis, \& J. Pinto (Eds.), Foundations of Computer-Aided Process Operations. Savannah, Georgia, USA.

Debellefontaine, H., \& Foussard, J. N. (2000). Wet air oxidation for the treatment of industrial wastes. chemical aspects, reactor design and industrial applications in europe. Waste Management, 20, 15-25. 
Djafer, M., Luck, F., Rose, J., \& Cretenot, D. (2000). Transforming sludge into a recyclable and valuable carbon source by wet air oxidation. Water Science and Technology, 41, 77-83. URL: http: //www. scopus. com/inward/record. url?eid=2-s2.0-0033861854\& partnerID=40\&md5=add57e711bd287b693e5d268301a603e.

Foussard, J., Debellefontaine, H., \& Besombes-Vailh. (1989). Efficient elimination of organic liquid wastes: Wet air oxidation. Journal of Environmental Engineering, 115, 367-385.

G, X., Cuetos, M., Garc A., \& Mor A. (2005). Evaluation of digestate stability from anaerobic process by thermogravimetric analysis. Thermochimica Acta, 426, 179 - 184. URL: http://www.sciencedirect. com/science/article/pii/S0040603104003442. doi:http://dx.doi.org/ $10.1016 /$ j.tca. 2004.07 .019 .

Himmelblau, D. (1960). Solubilities of inert gases in water, $0^{\circ} \mathrm{C}$ to near the critical point of water. J. Chem Eng Data, 5, 10-15.

Himmelblau, D. M. (1970). Process analysis by statistical methods. Wiley New York.

Khan, Y., Anderson, G. K., \& Elliott, D. J. (1999). Wet oxidation of activated sludge. Water Research, 33, 1681-1687.

Lei, R., Sopora, S., \& Gapes, D. (2013). The value of sludge. The Chemical Engineer, (pp. 38-41).

Lendormi, T., Prevot, C., Doppenberg, F., Foussard, J., \& Debellefontaine, H. (2001). Subcritical wet oxidation of municipal sewage sludge: comparison of batch and continuous experiments. Water Science \& Technology, 44, 161169.

Li, L., Chen, P., \& Gloyna, E. F. (1991). Generalized kinetic model for wet oxidation of organic compounds. AIChE Journal, 37, 1687-1697. 
Meille, V., Pestre, N., Fongarland, P., \& de Bellefon, C. (2004). Gas/liquid mass transfer in small laboratory batch reactors: Comparison of methods. Industrial \&3 Engineering Chemistry Research, 43, 924-927. URL: http://pubs.acs.org/doi/abs/10.1021/ie030569j. doi:10.1021/ ie030569j. arXiv:http://pubs.acs.org/doi/pdf/10.1021/ie030569j.

Mishra, V. S., Mahajani, V. V., \& Joshi, J. B. (1995). Wet air oxidation. Industrial 85 Engineering Chemistry Research, 34, 2-48.

Moreno, T., Kouzaki, G., Sasaki, M., Goto, M., \& Cocero, M. J. (2012). Uncatalysed wet oxidation of D-glucose with hydrogen peroxide and its combination with hydrothermal electrolysis. Carbohydrate Research, 349, 33-38.

Mucha, J., \& Zarzycki, R. (2008). Analysis of wet oxidation process after initial thermohydrolysis of excess sewage sludge. Water Research, 42, 3025 - 3032. URL: http://www.sciencedirect. com/science/article/pii/S0043135407007063. doi:http://dx.doi.org/ $10.1016 / j$. watres . 2007.11.012.

Potts, W. (2003). Guidelines for the safe application of biosolids to land in New Zealand. Technical Report ISBN 1-877134-43-0 Ministry of the Environment, New Zealand PO Box 1316, Wellington, NZ.

Prince-Pike, A. (2014). Modelling the Wet Oxidation Process of Municipal Biosolids. Ph.D. thesis Auckland University of Technology Auckland, New Zealand.

Shanableh, A. (2004). Generalized first-order kinetic model for biosolids decomposition and oxidation during hydrothermal treatment. Environmental Science 83 Technology, 39, 355-362.

Shanableh, A., \& Jomaa, S. (2005). Combined Sludge Treatment and Production of Useful Organic Substrate for Recycling - Evidence of Substrate Bioavailability to Support Biological Nutrient Removal. Arabian Journal for Science and Engineering, 30, 29. 
Strong, P., McDonald, B., \& Gapes, D. (2011). Enhancing denitrification using a carbon supplement generated from the wet oxidation of waste activated sludge. Bioresource Technology, 102, 5533-5540. URL: http://www.sciencedirect.com/science/article/pii/ S0960852410019553. doi:http://dx.doi.org/10.1016/j.biortech. 2010 . 12.025 .

Takamatsu, T., Hashimoto, I., \& Sioya, S. (1970). Model identification of wet-air oxidation process thermal decomposition. Water Research, 4, 33-59.

Van Amstel, J. J. A. P. (1971). The Oxidation of Sewage Sludge in the Liquid Water Phase at Elevated Temperatures and Pressures. Ph.D. thesis Technische Hogeschool te Eindhoven Eindhoven, Netherlands.

Van Amstel, J. J. A. P., \& Rietema, K. (1973). Wet-air oxidation of sewage sludge. Part II: The oxidation of real sludges. Chemie Ingenieur Technik, 45, $1205-1211$.

Verenich, S., \& Kallas, J. (2002). Wet oxidation lumped kinetic model for wastewater organic burden biodegradability prediction. Environmental Science \&3 Technology, 36, 3335-3339. URL: http: //pubs.acs.org/doi/abs/10.1021/es010244z. doi:10.1021/es010244z. arXiv:http://pubs.acs.org/doi/pdf/10.1021/es010244z.

Verenich, S., Laari, A., \& Kallas, J. (2003). Parameter Estimation and Sensitivity Analysis of Lumped Kinetic Models for Wet Oxidation of Concentrated Wastewaters. Industrial 83 Engineering Chemistry Research, 42, 5091-5098. URL: http://pubs.acs.org/doi/abs/10.1021/ie030134w. doi:10.1021/ ie030134w. arXiv:http://pubs.acs.org/doi/pdf/10.1021/ie030134w.

Zhang, Q., \& Chuang, K. T. (1999). Lumped kinetic model for catalytic wet oxidation of organic compounds in industrial wastewater. AIChE Journal, 45, 145-150. 
Zou, L., Li, Y., \& Hung, Y.-T. (2007). Wet air oxidation for waste treatment. In L. Wang, Y.-T. Hung, \& N. Shammas (Eds.), Advanced Physicochemical Treatment Technologies (pp. 575-610). Humana Press volume 5 of Handbook of Environmental Engineering. URL: http://dx.doi.org/10.1007/ 978-1-59745-173-4_13. doi:10.1007/978-1-59745-173-4_13. 